\title{
Avaliação Formativa na Educação a Distância: Concepções da Equipe Multidisciplinar de um Curso de Pós-Graduação em Informática na Educação
}

Formative Assessment in Distance Education: Conceptions of the Multidisciplinary Team of a Postgraduate Course in Informatics in Education

\section{Marize Lyra Silva Passos*}

Instituto Federal do Espírito Santo (IFES) - Rua Barão de Mauá, 30 Jucutuquara. Vitória, ES - Brasil.

\section{*marize@ifes.edu.br}

\section{Resumo}

A avaliação da aprendizagem é um tema que, nos dias atuais, ainda gera inquietação, principalmente quando parecem persistir concepções que produzem como resultados a classificação e a exclusão, quando o desejável é que propicie superações e aprendizagem. É nesse contexto que o presente artigo objetiva apresentar os resultados de uma pesquisa realizada no âmbito de um curso de pós-graduação lato sensu em Informática na Educação (PIE) ofertado pelo Instituto Federal do Espírito Santo na modalidade a distância; o trabalho buscou traçar um paralelo entre a avaliação formativa descrita em seu referencial teórico aqui delimitado e a práxis da equipe do curso. Por meio de uma abordagem quantiqualitativa e uma pesquisa exploratória e documental, analisamos a concepção de avaliação formativa que norteia o curso. Os dados foram coletados por meio de questionários, entrevistas, projeto pedagógico do curso, atas de reuniões e evidências obtidas nas salas virtuais de aprendizagem. Esses dados foram analisados apoiando-se na fundamentação teórica e sob a ótica da análise de conteúdos proposta por Bardin (2011). Como resultado final foi possível verificar que a equipe do curso encontra-se alinhada com o referencial teórico do tema, demonstrando que utiliza a avaliação formativa em seu cotidiano, apesar de que, em pequena escala, algumas falas remetam à avaliação classificatória.

Palavras-chave: Educação Superior. Avaliação da aprendizagem. Avaliação formativa. Informática na Educação. 


\section{Formative Assessment in Distance Education: Conceptions of the Multidisciplinary Team of a Postgraduate Course in Informatics in Education}

\begin{abstract}
Learning evaluation is a subject that today still generates restlessness, especially when there seem to be persistent conceptions that produce classification and exclusion as results, when it is desirable to provide overcomes and learning. In distance education there is no difference. It is in this context that the present article aims to present the results of a research carried out within the scope of a postgraduate course in Informatics in Education (PIE), offered by the Federal Institute of Espirito Santo in the distance learning modality, which sought to draw a parallel between the formative assessment described in its theoretical framework delimited here and the praxis of the team of the course. Through a quantitative and qualitative approach and an exploratory and documentary research, we analyze the conception of the formative evaluation that guides the course. The data were collected through questionnaires, interviews, pedagogical project of the course, minutes of meetings and evidences obtained from the virtual environment. These were analyzed based on the theoretical basis and from the point of view of the content analysis proposed by Bardin (2011). As a result, it was possible to verify that the course team is aligned with the theoretical framework on the subject, demonstrating that they use formative assessment in their daily lives, although, in a small scale, some statements refer to the classification evaluation.
\end{abstract}

Keywords: Higher education. Learning essessment. Formative essessment.

\section{Introdução}

A inserção da Educação a Distância (EaD) como modalidade de ensino nas universidades teve seu crescimento impulsionado a partir do ano 2000, quando, entre outros fatores, houve a implantação de um marco legal, por meio da Lei de Diretrizes e Bases da Educação Nacional (LDB), de 1996. Tal inclusão deveu-se à transformação da EaD em política pública do governo e teve como objetivo atender às necessidades dos governos e organizações de capacitar os agentes dispersos territorialmente (GONÇALVES, 2012).

No Brasil, os cursos superiores ofertados na modalidade a distância tiveram grande crescimento no início do século XXI, o que "tem se mostrado excepcional para a democratização do conhecimento e, também, bastante rico em termos de potenciais pedagógicos" (MILL, 2011, p. 280). A procura por cursos ofertados na modalidade tem crescido vertiginosamente. Segundo o Censo EAD.BR 2017/2018, realizado pela Associação Brasileira de Educação a Distância (ABED), ao longo dos anos foi observado "um crescimento muito acentuado nessa modalidade de ensino e aprendizagem e a consolidação de práticas exitosas para levar educação a todos os cantos do país e a todas as pessoas que desejam estudar em locais e horários flexíveis" (ABED, 2018, p. 29); ainda de acordo com o mesmo censo, "do total de 11.008 polos contabilizados pelo Censo EAD.BR 2017, 3.137 foram criados em 2017 e somente 137 foram fechados" (ABED, 2018, p. 55). Além disso, "nos últimos anos, os cursos em Educação a Distância (EaD) apresentaram maior crescimento no número de matrículas" (ABED, 2018, p. 25), passando de 3.734 .887 matrículas em 2017 para 7.773.828 matrículas no ano de 2018, o que representa um aumento de 108\% (ABED, 2018). 
Para garantia da qualidade dos cursos a distância, é necessário que se procure a todo momento avançar em sua compreensão devido ao seu caráter dinâmico; para isso, é necessário que se utilizem métodos de pesquisa que atendam a esse caráter. Lüdke e André (2012, p. 5) afirmam que "um dos desafios atualmente lançados à pesquisa educacional é exatamente o de tentar captar essa realidade dinâmica e complexa do seu objeto de estudo, em sua realidade histórica".

Entre os temas de interesse da Educação a Distância, pode-se destacar a avaliação da aprendizagem, a qual tem sido debatida por grupos cada vez maiores de educadores, preocupados com as suas práticas nas escolas e nas universidades. Segundo Polak (2009, p. 157-158), diante da "complexidade do tema, da legislação, da insatisfação do aluno e da comunidade acadêmica com as formas de avaliação vigentes, faz-se necessário que haja maiores investimentos para a pesquisa na área, tanto no que concerne aos aspectos pedagógicos quanto no que diz respeito às questões tecnológicas e administrativas da avaliação".

A EaD pode ser vista como uma cultura escolar diferenciada, que exige novos procedimentos para o acompanhamento da avaliação da aprendizagem (KENSKI, 2010). Este artigo constitui um relato de uma pesquisa que teve por objetivo evidenciar como a concepção e as características da avaliação formativa enunciadas pelos docentes que atuam na modalidade a distância em uma instituição de ensino pública brasileira encontram correspondência com o proposto pela teoria. Para isso, foi imprescindível o contato direto com a realidade a partir de conversas com os participantes, nas quais se buscou ouvi-los, interpretar seus discursos, desvelar suas percepções e compreender os significados atribuídos por eles à avaliação formativa.

\section{Avaliação Formativa}

Na década de 30, Ralph Tyler utilizou pela primeira vez o termo "avaliação da aprendizagem", cujo conceito foi complementado por Michael Scriven (1967) quando diferenciou o papel formativo do papel somativo na avaliação, cunhando pela primeira vez o termo "avaliação formativa" (VILLAS BOAS, 2011). Apesar de a avaliação formativa ter sido proposta por Scriven (1967) há mais de 40 anos, somente nos últimos anos ganhou destaque. Entretanto, na EaD, a avaliação formativa tem se mostrado uma excelente alternativa, visto que propicia aos professores um acompanhamento mais próximo de seus alunos, além de permitir que ambos acompanhem o processo de ensino-aprendizagem (DUTRA; PASSERINO; TAROUCO, 2010).

A avaliação formativa, diferentemente da classificatória, não tem o objetivo de classificar ou selecionar alunos; pelo contrário, é realizada com o objetivo de ajudar os alunos a aprender e a se desenvolver (PERRENOUD, 1999). Ela se fundamenta nos processos de aprendizagem, baseada em seus aspectos cognitivos, afetivos e relacionais e tem como fundamento a aprendizagem significativa e funcional aplicada em diversos contextos. Hoffmann (2005, p. 37) salienta que "avalia-se para formar aprendizes por toda a vida, para preservar e garantir a dignidade de crianças e jovens, sua segurança, sua liberdade, sua confiança na humanidade".

Villas Boas (2011, p. 19) afirma que, no Brasil, somente "nos últimos anos é que a expressão avaliação formativa se expandiu e as suas práticas começaram a adentrar as escolas, coincidindo com as iniciativas de democratização do acesso à educação". Então nada mais justo do que expandir ainda mais esse conceito para a Educação a Distância.

A avaliação é formativa na medida em que o desempenho do aluno é estimulado, interpretado e utilizado por professores, alunos ou seus pares para tomar decisões sobre os próximos passos do processo ensino-aprendizagem, visando fornecer feedback contínuo a alunos para que possam melhorar sua aprendizagem e, para professores, para que estes possam melhorar o ensino. Ela deve ocorrer durante a aprendizagem, e não depois da aprendizagem (SPECTOR et al., 2016; BLACK; WILIAM, 2009; POPHAM, 2008). 
Nesse enfoque, o princípio fundamental é avaliar o que se ensina; o processo avaliativo é parte integrante do processo ensino-aprendizagem. Pode-se, então, nesse contexto, falar em avaliação inicial, para avaliar e conhecer melhor o aluno visando a direcionar o processo, e avaliação final, para avaliar o resultado obtido ao finalizar um determinado processo didático. Nesse sentido, se a avaliação contribuir para o desenvolvimento das habilidades e capacidades dos alunos, pode-se dizer que ela se transforma em uma ferramenta pedagógica, em um elemento para melhorar a aprendizagem e a qualidade do ensino.

\section{Avaliação Formativa na Educação a Distância}

Depois de anos de atividades escolares em ambientes presenciais, alunos e professores estão vivenciando uma nova cultura escolar baseada em ambientes virtuais apoiados pelas tecnologias digitais da informação e comunicação (TDIC). Estamos em plena era da Educação a Distância, mais precisamente na educação online. Peters (2011, p. 33) afirma que a educação online "é didaticamente híbrida, o que proporciona à Educação a Distância uma flexibilidade ainda maior e um enorme potencial didático de mudanças".

Essas mudanças se refletem em todo o planejamento do processo ensino-aprendizagem e na avaliação da aprendizagem. Segundo Kenski (2010, p. 60), essa educação, "com seus espaços, tempos e procedimentos diferenciados, é, por si só, diferente. Como nova forma de se fazer educação, fascina e entusiasma a muitos".

Polak (2009, p. 153-154) afirma que a "a avaliação em EaD é um processo dinâmico, aberto e contextualizado que ocorre em um período, não sendo uma ação pontual e isolada" e que sua implantação "nos faz conviver com um novo momento, com uma nova forma de pensar e de ver a avaliação, dado que o modelo classificatório, monodirecional e quantitativo já não satisfaz as exigências de novas metodologias de ensino e de trabalho". Isso leva os educadores a buscar uma avaliação que ajude na formação integral de pessoas capazes de realizar tarefas, construir novos conhecimentos e resolver problemas, permitindo que "cada professor/monitor encontre seu estilo pessoal de lecionar, no qual se sinta confortável e realize melhor os objetivos, com avaliação contínua, aberta e coerente" (VALENTE; MORAN; ARANTES, 2011, p. 67).

Nessa nova abordagem, os alunos da EaD "têm que desenvolver, se acostumar e até mesmo internalizar uma nova abordagem, porque têm de organizar a sua aprendizagem de forma independente". Eles "têm que ser ativos não apenas ao executar suas tarefas de aprender, mas também ao interpretar e refletir criticamente sobre o que estão fazendo quando aprendem" (PETERS, 2009, p. 72), isso tudo auxiliado por ambientes de aprendizagem interativos e colaborativos. Então, para esse modelo educacional obter êxito é necessário haver uma avaliação processual que privilegie o monitoramento, o feedback contínuo e a preocupação do professor com a orientação do processo de aprendizagem, sendo ele um parceiro dos alunos ao mediar esse processo.

A avaliação da aprendizagem, seja ela no ensino presencial, seja a distância, "deve ser um instrumento de apoio e de contínua motivação necessária ao processo de construção do conhecimento", deixando simplesmente de aferir os conhecimentos dos alunos e passando "a ser um instrumento para modificação de práticas, redefinição de estratégias de aprendizagens, replanejamento de metas e objetivos", além de ser um instrumento de inclusão (POLAK, 2009, p. 153).

Em comparação com a sala de aula tradicional, a Educação a Distância apresenta diferentes problemas educacionais. No planejamento das atividades para cursos a distância, muitos autores condenam a utilização dos mesmos instrumentos de avaliação dos cursos tradicionais nos cursos a distância online. Todos consideram que, para atender às especificidades da EaD, a avaliação dos alunos não deve ser feita somente por meio do uso de provas e trabalhos; deve-se procurar obter informações pelo uso de diferentes ferramentas (KARAL; CEBI, 2012; KENSKI, 2010). Essa ideia é corroborada por Villas Boas (2011) quando 
afirma que o professor precisa cruzar as informações obtidas por meio de atividades formais e informais realizadas pelos alunos, tendo com isso um panorama mais realista de seu desenvolvimento.

Por essa e outras razões, Polak (2009, p. 153) afirma que "é indiscutível a necessidade de que sejam revistos e aperfeiçoados os métodos avaliativos em EaD" e que esse novo enfoque visa à geração de informações e comunicações que permitam o monitoramento, o apoio e o aperfeiçoamento dos alunos e do sistema, o que exige um acompanhamento que seja mais formativo do que classificatório (POLAK, 2009).

$\mathrm{Na} \mathrm{EaD}$, a avaliação deve ser significativa e se preocupar com a aprendizado do aluno, ajudando-o na sua trajetória em busca do conhecimento e no modo como seus resultados serão usados. Nessa perspectiva, tem-se a avaliação formativa, que é realizada com o objetivo de ajudar o aluno a aprender e a se desenvolver (PERRENOUD, 1999). Para atender a essas características esperadas da avaliação, é necessário pensar esse processo avaliativo como avaliação formativa, considerando o que se propõe: um processo contínuo de verificação do progresso e acompanhamento do estudante, bem como identificação das dificuldades que eles apresentam para que elas sejam sanadas ainda durante o processo, pois nela

encontram-se reunidas todas as possibilidades de apoio ao estudante ao longo de sua trajetória, levando em conta seus interesses, aspirações, experiências e reais necessidades. Tal modalidade caracteriza-se pela ocorrência contínua e processual, permeando toda a estratégia pedagógica do curso. Ao acompanhar a ação de ensinar e de aprender, permite verificar a compatibilidade entre os objetivos direcionadores do processo ensino-aprendizagem e os resultados efetivamente alcançados (KENSKI; OLIVEIRA; CLEMENTINO, 2006, p. 81).

Contextualizada, essa avaliação é capaz de fornecer feedbacks aos alunos e professores para que, por intermédio de suas intervenções no processo ensino-aprendizagem, sejam capazes de garantir a qualidade aos cursos online, tornando a avaliação formativa crucial para o aprendizado online individualizado, pois o feedback imediato fornecido na avaliação online formativa e assistida por computador permite que os alunos se autoavaliem e se aprimorem de imediato (TSAl; TSAl; LIN, 2015).

\section{Metodologia}

Como já mencionado, este artigo apresenta os resultados de uma pesquisa realizada no âmbito do curso de pós-graduação lato sensu em Informática na Educação (PIE) ofertado pelo Instituto Federal do Espírito Santo na modalidade a distância. Por meio de uma abordagem quantiqualitativa, empreendemos uma pesquisa bibliográfica com finalidade descritiva, exploratória e documental para analisar a concepção de avaliação formativa que norteia o curso.

Os dados foram produzidos com base em questionários, entrevistas, projeto pedagógico do curso, atas de reuniões e evidências obtidas a partir das salas virtuais de aprendizagem. Eles foram analisados apoiando-se na fundamentação teórica e sob a ótica da análise de conteúdos proposta por Bardin (2011). Participaram dessa pesquisa profissionais da educação com mais de 41 anos, predominantemente do sexo feminino, que atuam em mais de uma função (professor, tutor, pedagogo, coordenador etc.) e em mais de uma disciplina. A maioria atua na área de Educação há mais de dez anos e possui mais de cinco anos de experiência com curso a distância. 


\section{Resultados e Discussão}

O levantamento de dados foi realizado com base em pesquisa documental, baseado em registros nas salas virtuais e atas de reuniões iniciais, intermediárias e finais das disciplinas e aplicação de questionário para levantamento de informações acerca da percepção dos envolvidos na pesquisa; questionário e entrevista individual buscando levar os envolvidos à reflexão sobre sua prática, destacando seus saberes e fazeres sobre a avaliação formativa. Toda esta documentação foi importada e codificada no software para análise de dados NVivo 10 (Figura 1).

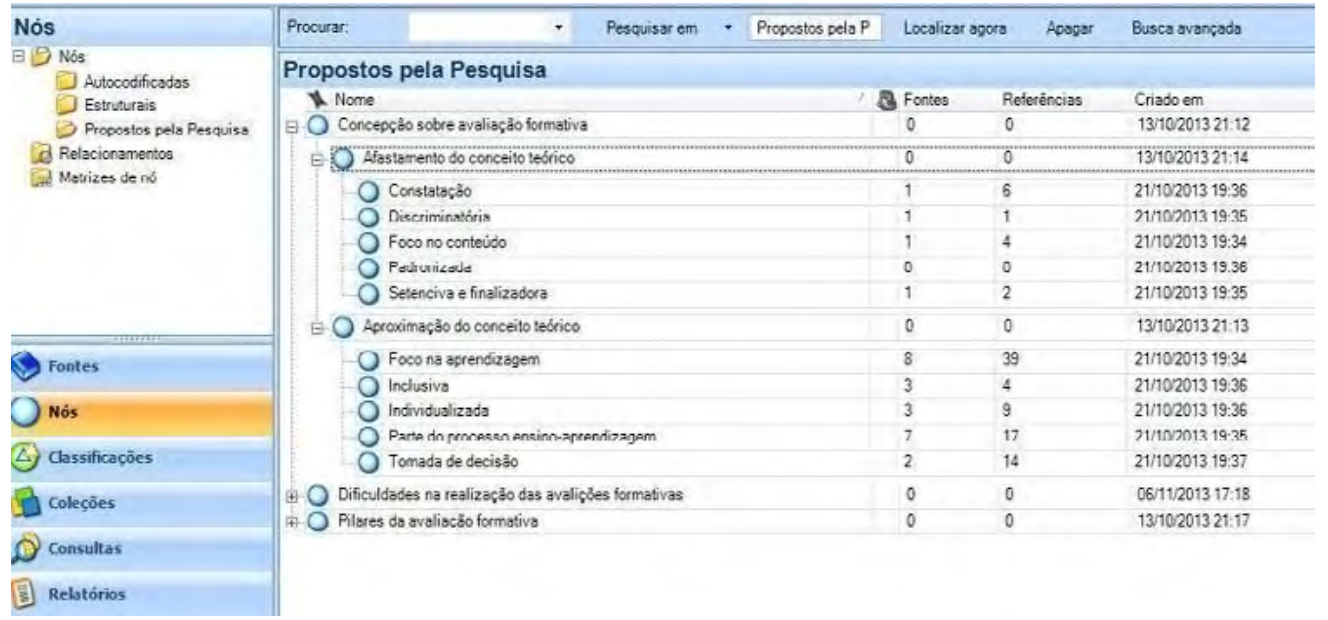

Figura 1: Codificação proposta pela pesquisa e cadastrada no NVivo 10 Fonte: Resultado do cadastramento e tratamento de dados no NVivo 10.

Antes de se iniciar esta análise, é importante ressaltar que a instituição, em seu projeto pedagógico institucional, defende que a avaliação da aprendizagem seja mais que mera constatação de resultados; isto é, seja uma prática pedagógica de transformação, na qual o ato de avaliar seja mais do que um ato de rotular os sujeitos por padrões ou classificações. A avaliação deve ser um processo de crescimento que leve a comunidade acadêmica a refletir sobre suas práticas e a desenvolver a autonomia.

Além disso, o projeto pedagógico da PIE defende que "as atividades de avaliação devem permitir avaliar os avanços do aprendiz no desenvolvimento das competências/habilidades de interesse". A avaliação da aprendizagem, por sua vez, só terá sentido no curso se servir para reorientar o aprendiz no desenvolvimento das aprendizagens e, aos professores, para o replanejamento de suas atividades. Não pode ser, pois, meramente classificatória, mas uma ferramenta construtiva, que promova melhorias e inovações com vistas ao aperfeiçoamento da aprendizagem dos estudantes.

Então, pode-se afirmar que a avaliação da aprendizagem que a instituição e a PIE defendem é a formativa. Por isso, é importante que tenhamos claro qual a concepção sobre a avaliação da aprendizagem que a equipe do curso PIE possui e o quanto ela se encontra próxima ou afastada do referencial teórico sobre a avaliação formativa.

Com base na definição das categorias citadas no Quadro 1, essa classificação sistemática da trama textual em função das unidades de registro permitiu colocar em relevo as informações obtidas, facilitando realizar inferências; ou seja, deduzir, de maneira lógica, conhecimentos relativos à temática discutida (BARDIN, 2011). Só então a descrição e a interpretação das manifestações dos sujeitos, articulando-as ao problema e aos objetivos do estudo, puderam ser concluídas.

Quanto ao tipo de avaliação que é utilizada no curso PIE, tem-se que $52 \%$ dos membros da equipe multidisciplinar participantes da pesquisa consideram que no curso PIE são usados os dois tipos de avaliação: 
a classificatória e a formativa; $22 \%$ consideram que o tipo de avaliação que é usada depende da disciplina e $26 \%$ consideram que a avaliação formativa é a mais utilizada, conforme se pode ver no Gráfico 1.

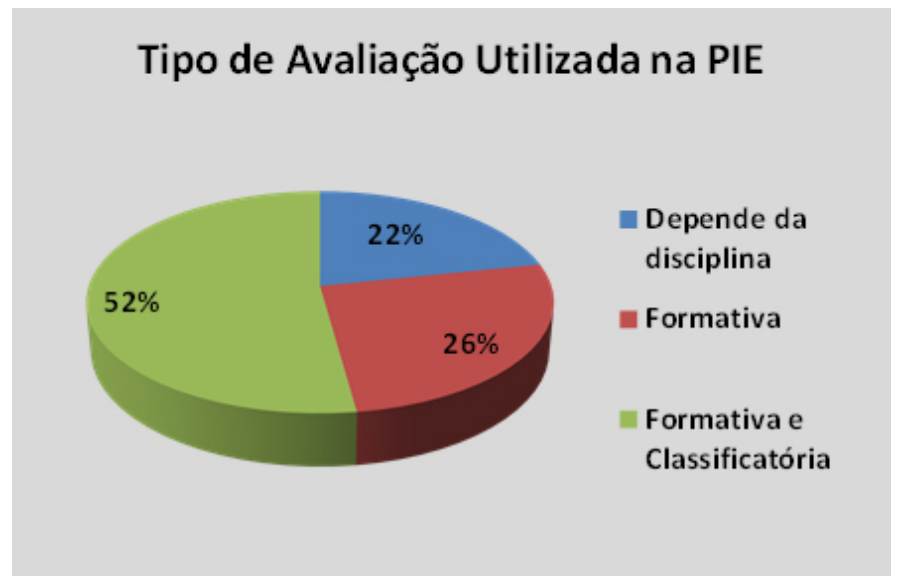

Gráfico 1: Tipo de avaliação utilizada na PIE segundo os membros da equipe multidisciplinar Fonte: Resultado do questionário aplicado aos sujeitos da pesquisa.

Para corroborar esses dados, foi analisado no planejamento das disciplinas se as avaliações tinham como foco principal a aprendizagem, uma das principais características das avaliações formativas. No Gráfico 2 nota-se que 83\% das atividades têm como foco a aprendizagem, o que demonstra que a percepção da equipe da PIE é pertinente.

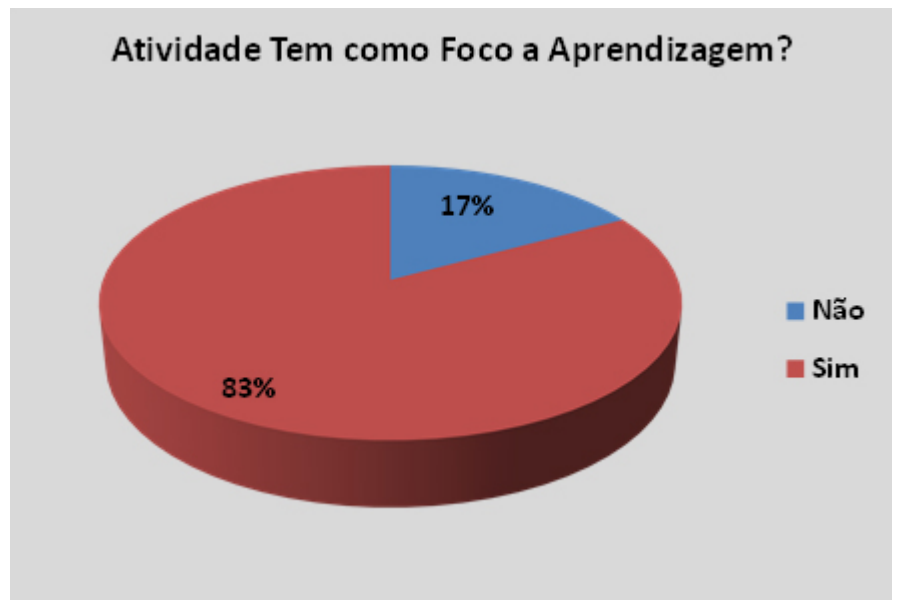

Gráfico 2: Quantidade de atividades avaliativas com foco na aprendizagem Fonte: Resultado da análise do planejamento das disciplinas do curso PIE.

Isso evidencia que a avaliação formativa é uma constante na prática pedagógica do curso, uma vez que nas respostas "Ambas" e "Depende da disciplina" a avaliação formativa encontra-se embutida. O valor de $52 \%$ de utilização de ambos os tipos de avaliação não é surpresa, uma vez que a própria legislação nos remete a essa prática.

Mas como a legislação dá margem para a escolha dos tipos de "exames" a serem utilizados de acordo com o projeto pedagógico do curso ou programa, no caso do curso PIE há a prerrogativa da realização de avaliação formativa tanto nas atividades a distância como nas presenciais. Isso fica evidente no projeto pedagógico do curso, que afirma que qualquer que seja o método ou instrumento, eles devem contribuir com o aprendizado dos estudantes. 
As categorias apresentadas na Tabela 1 foram utilizadas para analisar a aproximação ou o afastamento apresentado pelos sujeitos da pesquisa; em relação à avaliação formativa, essa análise foi construída levando em conta as principais contradições que existem entre a concepção da avaliação classificatória e a da avaliação formativa.

As diversas leituras do material textual - questões abertas dos questionários e das entrevistas - permitiram que fosse identificado que a equipe multidisciplinar da PIE, em sua grande maioria, demonstra possuir uma concepção bem alinhada com os referenciais teóricos que fundamentam a avaliação da aprendizagem formativa que é preconizada no projeto pedagógico do curso (PPC) e no projeto pedagógico institucional (PPI). Além disso, os sujeitos da pesquisa afirmam que possuem familiaridade com a avaliação formativa e que se encontram à vontade para planejar e executar atividades avaliativas formativas. Desses, $61 \%$ sentem-se à vontade, mas $18 \%$ não se sentem totalmente à vontade para planejar e realizar atividades avaliativas, enquanto somente $4 \%$ afirmaram que não se sentem à vontade em planejar e executar esse tipo de avaliação.

Isso fica claro nos resultados apresentados na Tabela 1, na qual se verifica também que 14\% das falas dos sujeitos afastam-se desse conceito e que alguns sujeitos apresentam uma mescla dos dois conceitos em suas falas. A seguir, veremos o que esses sujeitos falam sobre as concepções da avaliação formativa.

Tabela 1: Concepção de avaliação formativa expressa pela equipe multidisciplinar

\begin{tabular}{|c|c|c|c|c|}
\hline Subcategorias & Unidades de registro & Indicações & $\%$ & $\%$ \\
\hline \multirow{5}{*}{$\begin{array}{l}\text { Aproximação do } \\
\text { conceito teórico }\end{array}$} & Foco na aprendizagem & 39 & $41 \%$ & \multirow{5}{*}{$86 \%$} \\
\hline & Inclusiva & 4 & $4 \%$ & \\
\hline & Individualizada & 9 & $9 \%$ & \\
\hline & $\begin{array}{l}\text { Parte do processo ensino-apren- } \\
\text { dizagem }\end{array}$ & 17 & $18 \%$ & \\
\hline & Tomada de decisão & 14 & $15 \%$ & \\
\hline \multirow{5}{*}{$\begin{array}{l}\text { Afastamento do } \\
\text { conceito teórico }\end{array}$} & Constatação & 6 & $6 \%$ & \multirow{5}{*}{$14 \%$} \\
\hline & Discriminatória & 1 & $1 \%$ & \\
\hline & Foco no conteúdo & 4 & $4 \%$ & \\
\hline & Padronizada & 0 & $0 \%$ & \\
\hline & Sentenciva e finalizadora & 2 & $2 \%$ & \\
\hline \multicolumn{2}{|l|}{ Total } & 96 & $100 \%$ & $100 \%$ \\
\hline
\end{tabular}

Fonte: Elaboração própria a partir das informações tratadas na pesquisa.

A avaliação formativa deve ter como foco central a aprendizagem do aluno; ou seja, ela visa à "aprendizagem do estudante em todos os sentidos, inclusive o da formação do cidadão para que ele tenha inserção social crítica" (VILLAS BOAS, 2011, p. 31-32). E, como afirma Freire (2011, p. 47), "ensinar não é transferir conhecimento, mas criar as possibilidades para a sua própria produção ou a sua construção".

Vê-se no discurso dos sujeitos da pesquisa que a unidade "Foco na aprendizagem" possui a maior quantidade de indicações, $41 \%$. A percepção dos membros da equipe multidisciplinar da PIE de que a avaliação tenha como foco a aprendizagem dos alunos pode ser vista claramente nas declarações feitas por eles, como se pode constatar em alguns relatos: 
É uma forma de fornecer subsídios para que o aluno compreenda o seu próprio processo de aprendizagem e o funcionamento de suas capacidades cognitivas que serão usadas na resolução de problemas (professora Ana, no questionário).

É a avaliação que contribui para a formação do aluno, para seu processo de aprendizagem e construção do conhecimento (professora Sara, no questionário).

Avaliação que leva em conta o processo de aprendizagem do aluno, e não apenas suas notas (professora Letícia, no questionário).

Uma avaliação que engloba mais fatores do que só dar a nota. Então, assim, é uma avaliação inicial com diagnóstico de como estão os alunos, onde eles estão em termo da aprendizagem, como levá-los a chegar ao objetivo (professora Silvia, em entrevista).

A tomada de decisão na avaliação formativa é uma peça-chave, não só no processo avaliativo, mas em todo o processo ensino-aprendizagem. Perrenoud (1999, p. 68) afirma que sempre "há espaço para ajustes, remanejos no meio do trajeto, [...], sobretudo as atitudes e as condutas dos alunos que manifestam seu interesse, sua compreensão, mas também suas resistências ou suas dificuldades para seguir o ritmo ou assimilar o conteúdo". Então é importante que os professores tenham a capacidade de fazer alterações em seus planejamentos em função dos feedbacks recebidos e da realidade de cada aluno. Essa atitude é responsável pelo sucesso da ação pedagógica e pela aprendizagem dos docentes.

Outra característica que foi muito enfatizada pelo grupo foi a de que a avaliação é parte integrante do processo ensino-aprendizagem, o que é defendido por autores como Villas Boas (2011, p. 7), que afirma que a avaliação formativa "não se refere simplesmente a técnicas ou instrumentos. Tem significado mais amplo, abrangendo os eventos de avaliação que ocorrem no dia a dia do trabalho escolar". A avaliação, nesse contexto, deixa de ser o término do processo de aprendizagem e passa a ser um processo de busca incessante da compreensão das dificuldades do educando, além de dinamizador de novas oportunidades de conhecimento (HOFFMANN, 2009a).

A indicação de que a avaliação da aprendizagem é parte integrante do processo ensino-aprendizagem consta de $18 \%$ das indicações na unidade de registro "parte do processo ensino-aprendizagem", como se pode ver nas falas de alguns dos membros da equipe multidisciplinar:

Bom, a avaliação, para mim, tem que acontecer ao longo do processo, então às vezes eu posso avaliar uma aula, uma discussão, não é só uma avaliação formal em que o aluno às vezes se sente sozinho para fazer isso, para mim avaliação ela é contínua é em todos os momentos (professora Helena, em entrevista).

Formativa pelo fato de que os alunos são avaliados ao longo do processo de aprendizagem da disciplina e também durante o desenvolvimento das atividades (professor Thiago, no questionário).

Avaliação formativa é aquela que se dá antes ou no decorrer do processo de ensino e aprendizagem (professora Vitória, no questionário).

Enquanto isso, a unidade de registro "Tomada de decisão" foi indicada em 15\% dos registros, o que pode ser constatado em algumas falas dos sujeitos: 
A partir dos dados obtidos nas avaliações, devemos tentar melhorar o processo ensino-aprendizagem (professora Adriana, no questionário).

Onde o aluno e o professor recebem feedback antes do término do percurso para que possam tomar novas direções em suas aprendizagens e ensino respectivamente (professor Thiago, no questionário).

Assim, medidas podem ser tomadas no decorrer do percurso para possibilitar que isso ocorra (professora Tatiana, no questionário).

As unidades de registro "Individualizada" e "Inclusiva" foram responsáveis por 9\% e 4\%, respectivamente. Na visão de Hoffmann (2009b, p. 62), a avaliação formativa

exige a observação individual de cada aluno, atenta ao seu momento no processo de construção do conhecimento, o que exige uma relação direta com ele a partir de muitas tarefas (orais ou escritas), interpretando-as (um respeito a tal subjetividade), refletindo e investigando teoricamente razões para soluções apresentadas, em termos de estágios evolutivos do pensamento, da área de conhecimento em questão, da experiência de vida do aluno.

A preocupação com a individualização da avaliação como parte integrante do processo ensino-aprendizagem pode ser vista, a seguir, nas falas dos professores:

Avaliação formativa é avaliar a ação do aluno como o sujeito a partir de um novo sistema de aprendizagem, estimulando a autocrítica e mensurando as expectativas, o potencial e as carências do aluno (professora Helena, no questionário).

Avaliar formativamente é entender que cada aluno possui seu próprio ritmo de aprendizagem e, sendo assim, possui cargas de conhecimentos diferentes entre si (professora Adriana, no questionário).

Avaliar formativamente envolve a compreensão de que cada aluno possui seu próprio ritmo de aprendizagem e diferentes repertórios de conhecimentos. É ter a compreensão de que avaliar não é só medir o conhecimento e classificar; avaliar envolve, também, respeitar o tempo de cada indivíduo, reconhecendo que a partir do erro pode-se sempre encontrar o caminho para o acerto (professora Elizabeth, no questionário).

Apesar de haver uma grande maioria de indicações que remetem à avaliação formativa, vale ressaltar que existem, entrecortadas ao discurso dos professores, algumas falas que remetem aos conceitos e procedimentos da avaliação classificatória, como se pode constatar a seguir:

São as formas de avaliarmos o desenvolvimento do aluno quanto à receptividade do conteúdo (professor Humberto, no questionário).

Classificatória, ao término das atividades e principalmente da disciplina, quando o aluno recebe uma nota e uma classificação se está apto ou não a continuar no curso (professor Thiago, no questionário).

Inicialmente, precisamos fazer uma avaliação classificatória para selecionar os alunos (professora Adriana, no questionário). 
Esse grupo possui familiaridade com a avaliação formativa e seus conceitos sobre o tema encontramse bem alinhados com a literatura, ainda que apresentem algumas preocupações com a realização desse tipo de avaliação, como os problemas relacionados à quantidade de tarefas e ao tempo para corrigi-las (46\%); a quantidade de alunos atendidos por tutor (25\%); e a necessidade de realização de planejamento prévio (17\%). Outros problemas citados em igual proporção (4\% cada) foram: o enraizamento da concepção classificatória de avaliação, tanto dos professores como dos alunos; a heterogeneidade existente entre os alunos; e a modalidade de ensino.

\section{Considerações Finais}

Neste trabalho buscou-se traçar um paralelo entre a avaliação formativa descrita no referencial teórico aqui delimitado e a práxis da equipe de um curso de pós-graduação lato sensu em Informática na Educação, ofertado na modalidade a distância em uma instituição de ensino superior brasileira.

Por meio de uma abordagem quantiqualitativa e uma pesquisa exploratória e documental, analisamos a concepção de avaliação formativa que norteia o curso; após análise das respostas dos membros da equipe multidisciplinar da PIE sobre suas concepções e percepções sobre avaliação formativa, vê-se que a maioria da equipe encontra-se alinhada com o referencial teórico do tema, demonstrando que utiliza a avaliação formativa em seu cotidiano, apesar de ainda apresentar, em pequena escala, algumas falas que remetem às referências de avaliação classificatória.

A sua grande maioria está preocupada em planejar suas avaliações com foco na aprendizagem do aluno e vê como parte integrante do processo ensino-aprendizagem, além de utilizar os feedbacks provenientes dessas atividades para poder tomar decisões sobre o andamento de sua disciplina, propor novos percursos para os alunos e ainda enxergar a avaliação como um processo que deve levar em conta os conhecimentos e o ritmo da aprendizagem de cada aluno.

Esses resultados evidenciam que a avaliação formativa é uma constante na prática pedagógica desse curso de pós-graduação lato sensu em Informática na Educação.

\section{Agradecimentos}

Agradeço a toda a equipe multidisciplinar do curso de Pós-graduação lato sensu em Informática na Educação que participou da pesquisa e se dispôs a pensar sua prática, contribuindo para que fosse possível a construção compartilhada do conhecimento.

\section{Referências Bibliográficas}

BARDIN, L. Análise de conteúdo. Trad. Luiz Antero Reto e Augusto Pinheiro. São Paulo: Edições 70, 2011.

BLACK, P.; WILIAM, D. Developing the theory of formative assessment. Educational assessment, evaluation and accountability, v. 21, n. 1, p. 5-31, fev. 2009.

DUTRA, R.; PASSERINO, L.; TAROUCO, L. Utilização de objetos de aprendizagem abertos SCORM para dar suporte à avaliação formativa. Revista Brasileira de Informática na Educação, v. 18, n. 3, 2010.

FREIRE, P. Pedagogia da Autonomia: saberes necessários à prática educativa. 43ª ed. São Paulo: Paz e Terra. 2011. 
GONÇALVES, M. B. R. de O. A inserção da EaD em uma instituição de ensino convencional. In: LITTO, F. M.; FORMIGA. M. (Orgs.). Educação a Distância: o estado da arte. Vol. 2. São Paulo: Pearson Education do Brasil, 2012. p. 294-302.

HOFFMANN, J. Avaliação: mito e desafio - uma perspectiva construtivista. 35ª ed. Porto Alegre: Mediação, 2009a.

Avaliação mediadora: uma prática em construção da pré-escola à universidade. $30^{a}$ ed. Porto Alegre: Mediação, 2009b.

O jogo do contrário em avaliação. 3a ed. Porto Alegre: Mediação, 2005.

KARAL, H., CEBI, A. Views on modular assessment and evaluation process in distance education. Procedia - Social and Behavioral Sciences, n. 46, p. 2.073-2.077, 2012.

KENSKI, V. M. Avaliação e acompanhamento da aprendizagem em ambientes virtuais a distância. In: MILL, D. R. S.; PIMENTEL, N. M. (Orgs.). Educação a distância: desafios contemporâneos. São Carlos: EdUFSCar, 2010. p. 59-68.

LÜDKE, Menga; ANDRÉ, Marli E. D. A. Pesquisa em educação: abordagens qualitativas. Reimpr. São Paulo: EPU, 2012.

MILL, D. A Universidade Aberta do Brasil. In: LITTO, F. M.; FORMIGA. M. (Orgs.). Educação a Distância: o estado da arte. Vol. 2. São Paulo: Pearson Education do Brasil, 2011. p. 280-291.

PERRENOUD, P. Avaliação: da excelência à regulação das aprendizagens - entre duas lógicas. Trad. Patrícia C. Ramos. Porto Alegre: Artmed, 1999.

PETERS, O. A Educação a Distância em transição: tendências e desafios. Trad. Leila Ferreira de Souza Mendes. São Leopoldo: Editora Unisinos, 2009.

Didática do Ensino a Distância. 3ª reimpr. São Leopoldo: Editora Unisinos, 2011.

POLAK, Y. N. de S. A avaliação da aprendizagem em EaD. In: LITTO, F. M.; FORMIGA, M. (Orgs.). Educação a Distância: o estado da arte. São Paulo: Pearson Prentice Hall, 2009. p. 153-159.

POPHAM, W. J. Transformative assessment. Chapter 1. Alexandria: Association for Supervision and Curriculum Development, 2008. Disponível em: http://www.ascd.org/publications/books/108018/chapters/Formative-Assessment@-Why,-What,-and-Whether.aspx. Acesso em: 28 abr. 2018.

VALENTE, J. A.; MORAN, J. M.; ARANTES, V. A. (Orgs.). Educação a Distância: pontos e contrapontos. São Paulo: Summus, 2011.

VILLAS BOAS, B. M. de F. (Org.). Avaliação formativa: práticas inovadoras. Campinas: Papirus, 2011. Coleção Magistério - Formação e Trabalho Pedagógico.

SCRIVEN, M. The Methodology of Evaluation. In: TYLER, R.; GAGNE, R.; SCRIVEN, M. Perspectives of Curriculum Evaluation. Washington, DC: American Educational Research Association, 1967.

SPECTOR, J. M.; IFENTHALER, D.; SAMSPON, D.; YANG, L.; MUKAMA, E.; WARUSAVITARANA, A. Technology enhanced formative assessment for 21st century learning. Educational Technology \& Society, v. 19(3), p. 58-71, 2016.

TSAI, Fu-Hsing; TSAI, Chin-Chung; LIN, Kuen-Yi. The evaluation of different gaming modes and feedback types on game-based formative assessment in an online learning environment. Computers \& Education, v. 81, p. 259-269, 2015. 